\title{
Laboratory measurement of dielectric constant and loss tangent of Indian rock samples
}

\author{
Ramesh P. Singh ${ }^{* *}$ - Mahandra P. Singh ${ }^{* *}$ - Tarkeshwar LaL ${ }^{* *}$
}

Received on June 20th, 1980

\begin{abstract}
The data on dielectric properties of Indian rock samples are very sparsely reported in the literature. Keeping this in view, we have carried out laboratory measurements of the dielectric constant and loss tangents of some samples of sandstone, quartzite, limestone, marble, dolerite and basalt. LCR bridge and Q-meter have been employed for measurements in the frequency range $10^{2}-10^{7} \mathrm{~Hz}$. The results have been presented in the form of variation of these parameters with frequency which show cha. racteristic features. Observations on the effect of moisture content of these samples on the dielectric properties have also been reported. Further, correlation of petrographic studies of rock samples with measured variations of dielectric properties has been attempted.
\end{abstract}

$\therefore$ Department of Geophysics, Banaras Hindu University, Varanasi - 221005, India

*k:: Department of Geology, Banaras Hindu University, Varanasi - 221005, India 


\section{RIASSUNTO}

Nella letteratura sono molto scarsi i dati sulle proprietà dielettriche di campioni di roccia indiana. Tenendo conto di ciò sono state effettuate in laboratorio misure della costante dielettrica e del coefficiente di perdita su alcuni campioni di arenaria, quarzite, calcare, marmo, dolerite e basalto.

Sono stati impiegati il ponte LCR e la misura di $Q$ per misure nell'intervallo di frequenza $10^{2}-10^{7} \mathrm{~Hz}$.

I risultati sono stati rappresentati sotto forma di variazione di questi parametri con la frequenza, che mostra particolari caratteristiche. Sono inoltre riportate osservazioni sull'effet to del contenuto di umidità di questi campioni sulle proprietà dielettriche. Infine sono stati fatti tentativi di correlare studi petrografici di campioni di roccia con variazioni misurate delle proprietà dielettriche.

\section{INTRODUCTION}

The laboratory measurements of electrical properties of earth's forming rocks and minerals have played an important role in developing electrical and electromagnetic prospecting method of mineral exploration (Keller and Frischknecht, 1966; Madden and Cantwell, 1967; Von Voorhis et al., 1973); in crustal sounding (Hermance, 1973); in lunar and planetary sounding (Banks, 1969; Brown, 1972; Dyal and Parkin, 1972) and in glacier sounding (Rossiter et al., 1973). In view of the growing importance of laboratory measurements of electrical properties and also keeping in view the scarcity of such data on Indian rocks, we have carried out measurement of dielectric constant and loss tangent of some Indian rock samples in the radio wave frequency range from $10^{2}-10^{7} \mathrm{~Hz}$ using LCR bridge and Q-meter.

In the present paper, we have reported the results of measurements of dielectric constant and loss tangent of two samples of sandstone, and one sample each of quartzites, marble, limestone, dolerite and basalt. We have further studied the influence of moisture content of the samples on these properties. Petrographic study of the samples has also been made and it has been attempted to correlate the observed features with variations of the dielectric properties of measured samples. 


\section{Sample Preparation and Measurement Technique}

Dielectric constant and loss tangent measurements on various rock samples have been carried out. The samples are cut in the shape of disks with a diameter of $2.54 \mathrm{~cm}$ and a thickness of $0.5 \mathrm{~cm}$. The two surfaces are grounded and finished with 600 mesh powder and made as plane and parallel as possible.

LCR bridge and Q-meter (Radart type 1202A) has been used for accurately measuring the capacitance of a circular parallel plate system with a specially prepared disk sample using two terminal technique. This technique has some inherent limitations and the measuring system is strongly affected by electrode size and shape, sample impedances, fringing fields and surface conduction around the samples. To improve the accuracy of measurements and to avoid above effects following precautions are taken:

i) Sample surfaces are made exactly parallel and as smooth as possible;

ii) Contact between electrodes and the rock sample are kept fairly tight, to ensure good contact without physically affecting the sample, and;

iii) Size of the sample is made exactly equal to the size of the electrode used in the measurement.

The accuracy of capacitance measurement by LCR bridge and $\mathrm{Q}$-meter is $\pm 2 \%$, and $\mathrm{D}$ measurements by $\mathrm{Q}$-meter is $\pm 5 \%$. The capacitance of the parallel plate system with air and the rock samples as dielectrics are determined. The capacitance of the parallel plate system with the rock sample and accounting for the stray capacitance due to sample holder, cables and other parts of the measuring system enables the determination of dielectric constant of the sample

$$
\varepsilon_{r}=\frac{\S_{0} A}{\Delta C d}+1
$$


where $\Delta C=$ difference in capacitance of circular parallel plate with the sample and without the sample.

$$
\begin{aligned}
& d=\text { thickness of the sample } \\
& A=\text { area of cross-section } \\
& \varepsilon_{0}=\text { permittivity of the free space. }
\end{aligned}
$$

The quality factors with and without the sample $Q_{1}$ and $Q_{2}$ respectively bear a simple relation with the total capacitance $C_{T}$ of the system with the rock sample. The loss tangent of the sample is given by

$$
D=\frac{C_{T}}{\Delta C+C_{\mathrm{o}}}\left(\frac{1}{Q_{1}}-\frac{1}{Q_{2}}\right)
$$

where $C_{0}$ is the capacitance of the circular parallel plate condenser without the sample and $\Delta C$ is the difference of capacitance with the rock specimen in and removed.

\section{SAMPLE DESCRIPTION}

Sample 1 (Vindhyan sandstone): It is fine grained, compact with silicious cementing material and pinkish in appearance. This sample mainly contains quartz, feldspar, mica and iron oxide.

Sample 2 (Vindhyan quartzite): It is whitish in appearance fine grained, compact with silicious cementing material. The sample contains mainly quartz.

Sample 3 (Baraker sandstone): The grains of this sample are nedium to coarse with inequigranular texture. The cementing material is argelacious which makes the sample fragile. The major constituents of the sample are quartz, feldspar, mica and hematite. The sample is grey in appearance with brownish specks (Plate 1). 
Sample 4 (Marble): The sample contains mainly calcite with other minor constituents. The rock is hard compact with a mosaic texture and is white in appearance.

Sample 5 (Limestone): The sample is fine grained, hard and compact, grey to dark black in colour. The specific gravity is near about 2.31. Under microscope, thin section of limestone sample shows fine grained calcite with thin calcite vein (Plate 2).

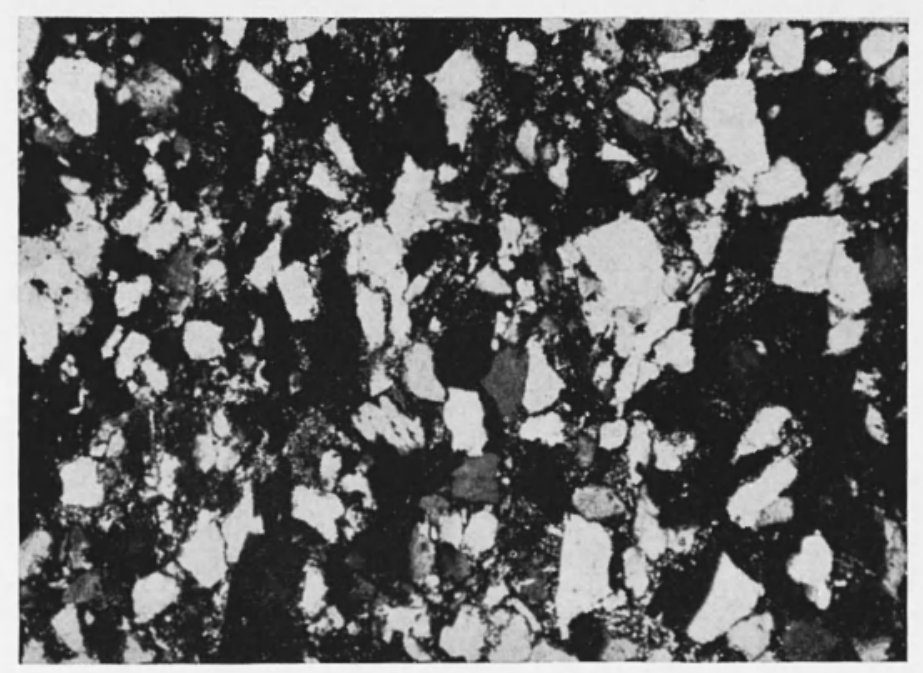

Plate 1 - Baraker sandstone

The main constituent is calcite (about 96\%). Quartz is present in the form of very minute grains whose number is very small. In the form of iron oxides, mainly magnetite is occurring in the form of minute grains. The chemical analysis of the sample has been carried out by spectrochemical methods, and the percentage of oxides on weight basis has been found as given in Table 1 .

Sample 6 (Dolerite): The sample shows black to greenish black colour. It is hard and compact and fine to medium grained. Under microscope, it shows fine to medium grains showing ophitic to subophitic texture. The plagioclases are the main mi- 


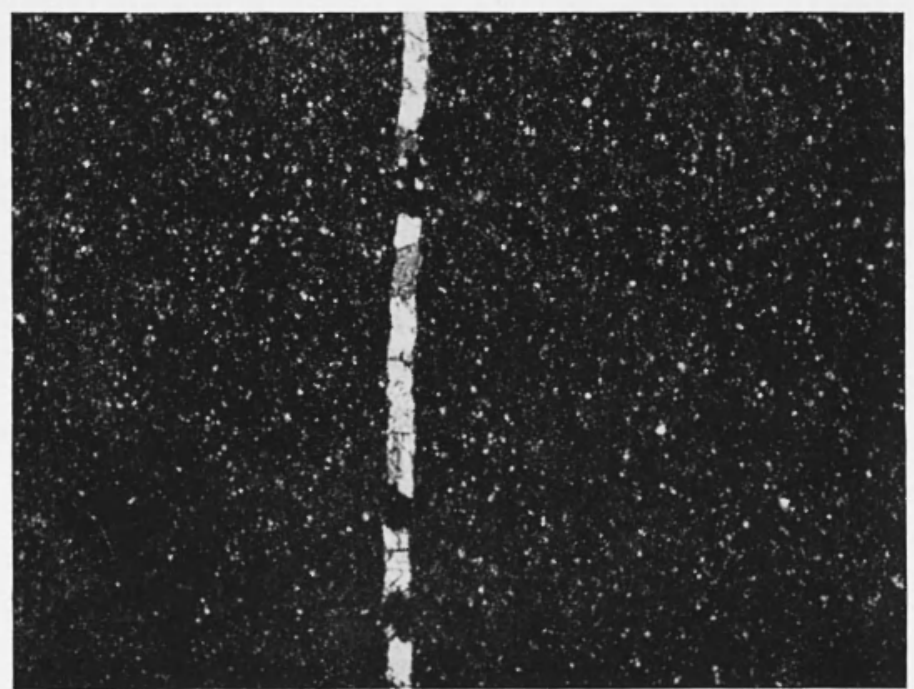

Plate 2 - Limestone

neral constituents occurring as phenocryst. The broad plagioclase laths (Plate 3) show zoning which is commonly found in these rocks.

TABLE 1

Chemical analysis of limestone

\begin{tabular}{|lc|lc|}
\hline Constituents & Weight \% & Ccnstituents & Weight \% \\
\cline { 1 - 4 } $\mathrm{SiO}_{2}$ & 3.94 & $\mathrm{TiO}_{2}$ & 0.22 \\
$\mathrm{Al}_{2} \mathrm{O}_{1}$ & 0.62 & $\mathrm{Fe}_{2} \mathrm{O}_{1}$ & 0.53 \\
$\mathrm{FeO}$ & 0.05 & $\mathrm{MnO}$ & 0.06 \\
$\mathrm{MgO}$ & 0.61 & $\mathrm{CaO}$ & 52.11 \\
$\mathrm{Na}_{2} \mathrm{O}$ & 0.21 & $\mathrm{M}, \mathrm{O}$ & 0.12 \\
$\mathrm{P}_{2} \mathrm{O}_{5}$ & 0.21 & $\mathrm{H}_{2} \mathrm{O}$ & 0.51 \\
$\mathrm{CO}$ & 40.80 & & \\
\hline
\end{tabular}




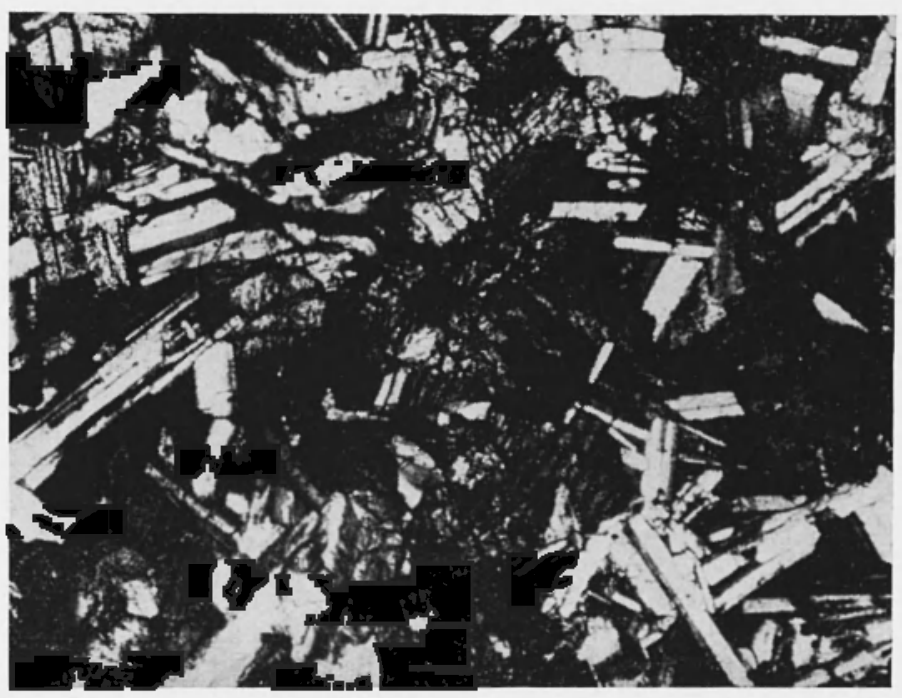

Plate 3 - Dolerite

Rods of magnetite are seen in some of plagioclase laths. Magnetite and illmenite are present in the rock in scattered manner. A fey patches of subhedral cystals of illmenite are also present. The model analysis and chemical analysis of the sample are given in Table 2 and 3 respectively.

TABLE 2

Model analysis of dolerite

\begin{tabular}{|c|c|}
\hline Mineral constituents & $\%$ \\
\hline Plagioclase & 42.15 \\
\hline Pyroxenes & 39.84 \\
\hline Iron oxides & 11.60 \\
\hline Glass and others & 6.40 \\
\hline & 99.99 \\
\hline
\end{tabular}


Sample 7 (Basalt): The sample is brownish black to black, fine grained with a number of vesicles. These vesicles are filled with the secondary minerals like zeolites, chalcedony, calcite etc. Under microscope, it shows glomeroporphyritic texture and is found to be composed of plagioclase, pyroxene, iron oxides and brown glass. As an alteration product, chlorites are seen in the thin section. The plagioclase shows two types which belong to

TABLE 3

Chemical analysis of dolerite

\begin{tabular}{|cc|cc|}
\hline Oxides & Weight $\%$ & Oxides & Weight $\%$ \\
$\mathrm{SiO}_{2}$ & 52.19 & $\mathrm{TiO}$ & 2.18 \\
$\mathrm{Al}_{2} \mathrm{O}_{3}$ & 13.66 & $\mathrm{Fe}_{2} \mathrm{O}_{2}$ & 5.48 \\
$\mathrm{FeO}$ & 7.45 & $\mathrm{MnO}$ & 0.19 \\
$\mathrm{MgO}$ & 5.20 & $\mathrm{CaO}$ & 9.41 \\
$\mathrm{Na}=\mathrm{O}$ & 2.35 & $\mathrm{~K}, \mathrm{O}$ & 0.61 \\
$\mathrm{P}_{2} \mathrm{O}$ & 0.20 & $\mathrm{H}_{2} \mathrm{O}$ & 2.75 \\
\hline
\end{tabular}

two generations; one forming long glomeroporphyritic aggregates and other forming small laths scattered through the ground mass. The layer crystals are much cracked and show zoning. The present pyroxene is mainly dominated by augite and occurs as subhedral grains of slightly brownish colour. Some grains of olivine are also seen in the thin section. The iron oxides are represented by magnetite, illmenite and hematite. Glass present in the thin section shows brown colour and occurs in the form of round patches (Plate 4).

The model analysis and chemical analysis of the sample are given in the table 4 and 5 . 


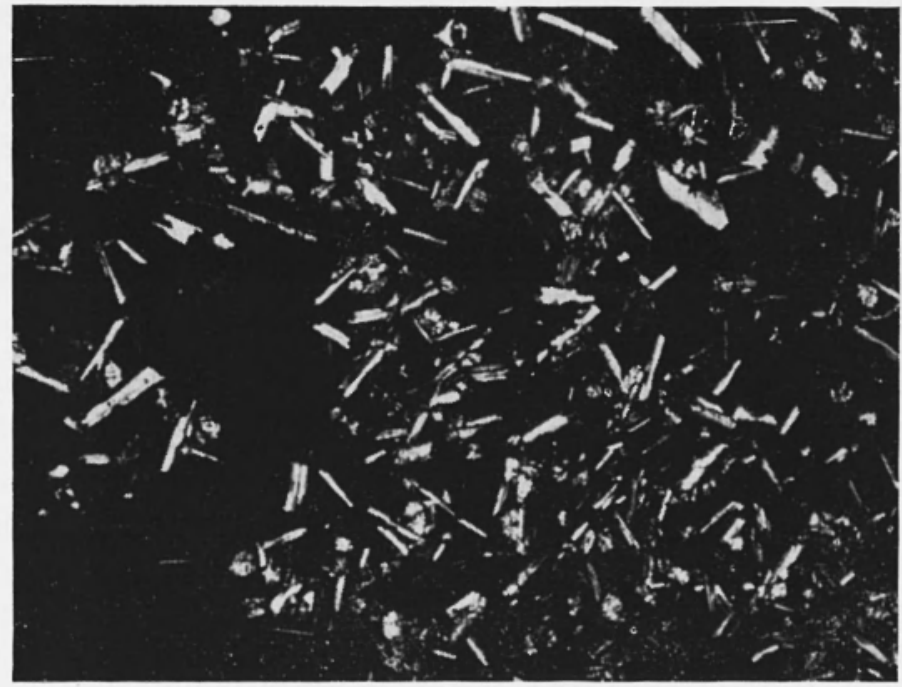

Plate 4 - Basalt

\section{RESUlTS AND DISCUSSIONS}

The measurements of dielectric constant and loss tangent of the above rock samples are made in the frequency range

TABLE 4

Model analysis of basalt

\begin{tabular}{|lc|}
\hline Mineral constituents & $\%$ \\
\hline Plagioclase & 40.58 \\
Pyroxene & 37.79 \\
Iron oxide & 8.42 \\
Glass and others & 13.20 \\
Total & 99.99 \\
\hline
\end{tabular}


$\left(10^{2}-10^{7} \mathrm{~Hz}\right)$ using LCR bridge and Q-meter. Results are presented in the form of variation of the dielectric properties of the samples with frequency. LCR bridge has been employed for the measurement in $10^{2}-10^{3} \mathrm{~Hz}$ range whereas measurements in $10^{5}$. $10^{7} \mathrm{~Hz}$ have been carried out by Q-meter owing to sensitivity reasons. With reference to the properties of 'dry' rock samples, the influence of moisture content are measured which are also described in the following discussion.

TABLE 5

Chemical analysis of basalt

\begin{tabular}{|cc|cc|}
\hline Oxides & Weight $\%$ & Oxides & Weight $\%$ \\
$\mathrm{SiO}:$ & 52.52 & $\mathrm{TiO}$ & 2.59 \\
$\mathrm{Al}_{2} \mathrm{O}_{3}$ & 13.87 & $\mathrm{Fe}_{2} \mathrm{O}_{3}$ & 4.42 \\
$\mathrm{FeO}$ & 6.89 & $\mathrm{MnO}$ & 0.16 \\
$\mathrm{MgO}$ & 5.43 & $\mathrm{CaO}$ & 9.93 \\
$\mathrm{Na}_{2} \mathrm{O}$ & 2.45 & $\mathrm{~K}_{2} \mathrm{O}$ & 1.54 \\
$\mathrm{P}_{2} \mathrm{O}_{3}$ & 0.17 & $\mathrm{H}_{2} \mathrm{O}$ & 2.38 \\
\hline
\end{tabular}

Properties of Dry Rock SAMple

Cut and polished samples were placed in a dry nitrogen atmosphere for more than 48 hour and were finally stored at room temperature for more that 24 hour before measurement. The samples thus prepared are called as 'dry' samples.

Sample $I$ (Vindhyan sandstone): The dielectric constant shows (Fig. 1) almost a constant value upto $10^{5} \mathrm{~Hz}$. Above $10^{5} \mathrm{~Hz}$, 
it shows a decrease in the value with the increasing frequency. The overall change in the value of dielectric constant is from 16 to 6 in the entire frequency range. The loss tangent of the sample as presented in Fig. 2 shows an increasing trend in the frequency range $10^{5}-10^{6} \mathrm{~Hz}$, whereas in the range $10^{6}-10^{7} \mathrm{~Hz}$, it decreases. The measurement of loss tangent by LCR bridge in the lower frequency range $10^{2}-10^{5} \mathrm{~Hz}$ is quite insensitive and is found unreliable.

Sample 2 (Vindhyan quartzite): The dielectric constant shows a comparatively smaller decrease from 15 to 12 in the frequency range $10^{2}-10^{6} \mathrm{~Hz}$ (Fig. 1). In the frequency range 1 $\mathrm{MHz}$ to $10 \mathrm{MHz}$, more or less constant value of dielectric constant is obtained. The nature of the dispersion in data points is consistent with dispersion reported for samples of similar composition by Keller and Licastro (1959) and Fuller and Ward (1970) but is somewhat smaller in magnitude. The variation of loss tangent with frequency (Fig. 2) shows a cyclic trend with maximum and minimum peacks which is similar to that reported by Saint-Amant and Strangway (1970) and Olhoeft (1976, 1977). The magnitude of minimum peaks is almost but the magnitude of maximum peaks varies having the highest value around $10^{7} \mathrm{~Hz}$. The value of loss tangent varies between $1.2 \times 10^{-3}$ to $3.0 \times 10^{-3}$. Repeated measurements have been made to ascertain this typical variation of loss tangent with frequency. The variations with frequency are large and suggestive of non-linear processes. The presence of conducting minor constituents may in the rock sample be responsible for such a behaviour.

Sample 3 (Barker sandstone): The dielectric constant presented in Fig. 1 for this sample is comparatively large. It shows a slight decrease in the value of dielectric constant upto $4 \times 10^{5} \mathrm{~Hz}$. The variation of dielectric constant in the frequency range of $10^{3}-4 \times 10^{5} \mathrm{~Hz}$ is from 32 to 25 . Above $4 \times 10^{5} \mathrm{~Hz}$, the dielectric constant sharply falls from 25 to 14 at $10^{7} \mathrm{~Hz}$. The minimum value of the dielectric constant of this sample is found to be comparable with the maximum value of sample no. 1 and no. 2 . The loss tangent measured in the frequency range $10^{5}-10^{7} \mathrm{~Hz}$ is found to show a higher value (Fig. 2). The variation shows a cyclic 
trend with two maxima and two minima. Samples 1 and 3 contain a trace of iron oxide which is likely to be responsible for higher loss tangent as compared to sample 2 (Katsube and Collett, 1976) (Fig. 2).

Sample 4 (Marble): Dielectric constant of marble shows a small decrease in its value with the increase in frequency (Fig. 1). The value of dielectric constant varies from 12 to 8 . The value of dielectric constant of similar sample has been reported by Lytle (1974), which compares well with our measurements. The loss tangent measurements (Fig. 2) show a number of maximand minima. The magnitude of minimum at high frequency namely $7 \mathrm{MHz}$ attains a value of $5 \times 10^{-4}$ which is fairly small. This indeed is curious but does not give any clue of its physical origin.

Sample 5 (Limestone): The dispersion of data points of dielectric constant for limestone sample is found to be the least and varies from 5 to 3 in the entire frequency range (Fig. 1). The loss tangent shows similar variations but is smaller in magnitude (Fig. 2). The loss tangent is found to be higler than for marble. The variations show two maxima and three minima in the entire frequency range. The minimum near $7 \mathrm{MHz}$ attains a fairly low value. This feature is similar to that observed in marble which has apparently similar chemical composition.

Sample 6 (Dolerite): Measurement of dielectric constant and loss tangent for this sample are presented in Figs. 1 and 2. The dielectric constant values show a slight decreasing trend in the range $10^{2}$ to $10^{6} \mathrm{~Hz}$. In between $10^{6}-10^{7} \mathrm{~Hz}$ i.e. higher frequency range, a peak is observed in the value of dielectric constant, this may be because of higher iron oxide content in the sample which is shown by the chemical analysis of the sample as also reported by Katsube and Collett (1971). Loss tangent of the sample shows a cyclic trend in the measured frequency range. The variations show a lower value in the frequency range $10^{\prime}-10^{6} \mathrm{~Hz}$. It shows a number of maxima and minima peaks in the measured frequency range.

Sample 7 (Basalt): It shows almost a constant value in the frequency range $10^{2}-4 \times 10^{5} \mathrm{~Hz}$ (Fig. 1). A decrease in the value 


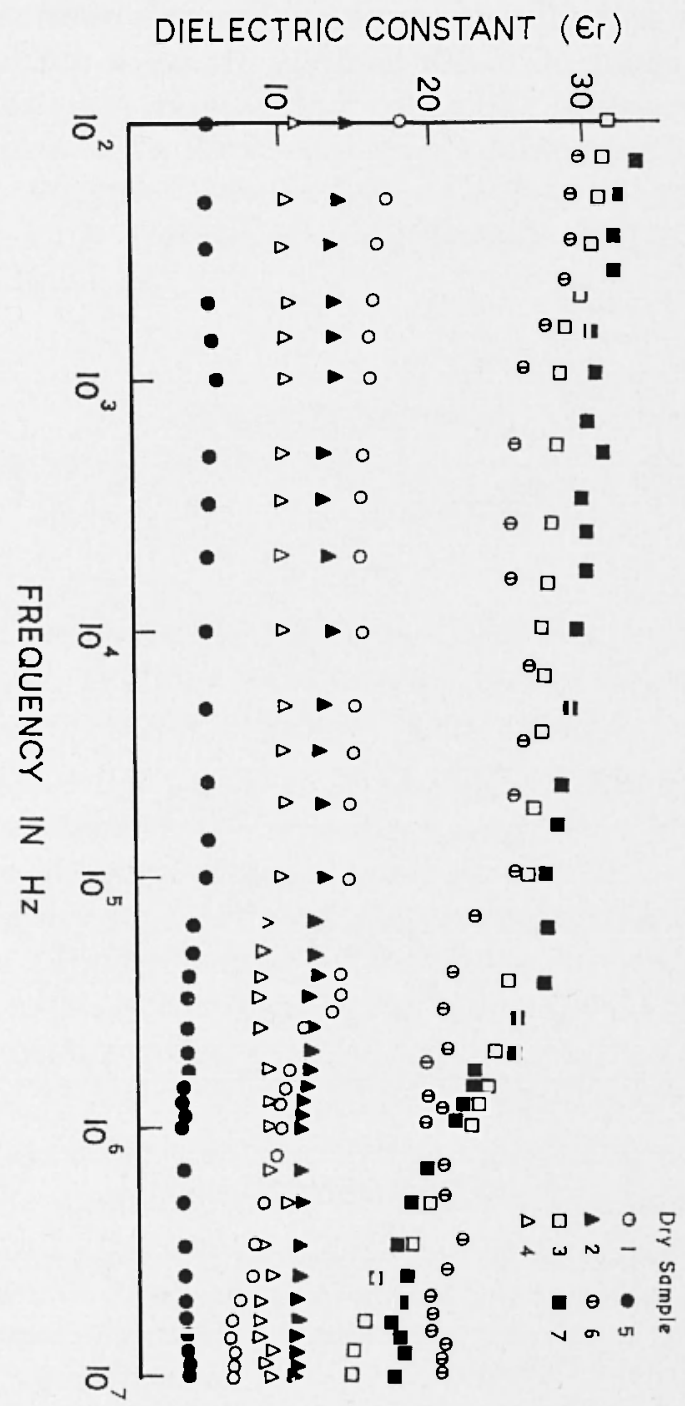

Fig. 1 - Variation of dielectric constant with frequency for dry samples (Sample 1 - Vindhyan sandstone, 2 - Vindhyan quartzite, 3 - Baraker sandstone, 4 - Marble, 5 - Limestone, 6 - Dolerite, 7 - Basalt). 
of dielectric constant is observed in the frequency range $4 \times 10^{5}$ $\mathrm{Hz}$ to $2 \mathrm{MHz}$ and afterwards the value gets saturated upto 10 $\mathrm{MHz}$. Loss tangent of basalt samples shows a much prominent

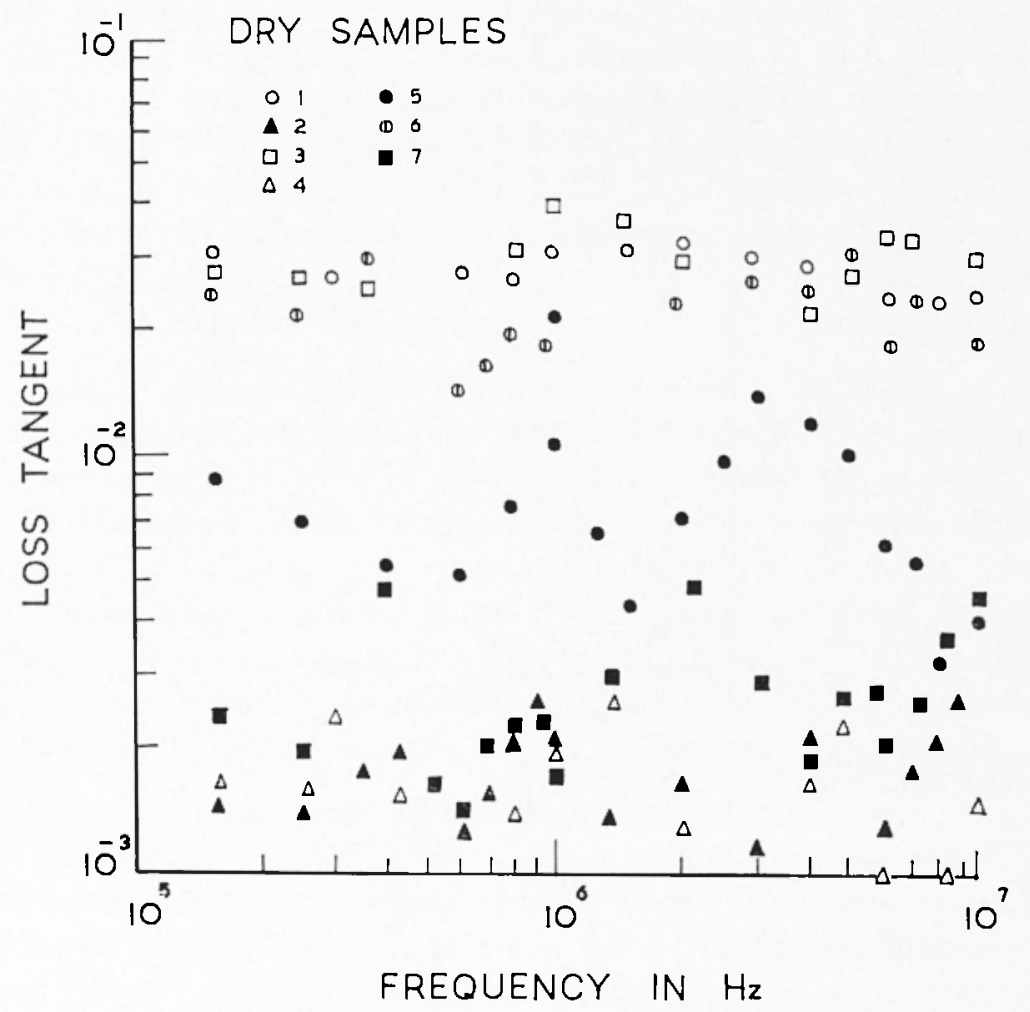

Fig. 2 - Variation of loss tangent with frequency for dry samples (Sample 1 - Vindhyan sandstone, 2 - Vindhyan quartzite, 3 - Baraker sandstone, 4 - Marble, 5 - Limestone, 6 - Dolerite, 7 - Basalt).

maxima and minima peaks (Fig. 2). Variation is similar to that shown by other volcanic rock sample (dolerite). The magnitude of loss tangent is smaller as compared to dolerite sample. 
INFLUENCE OF MOISTURE

Rocks samples were soaked overnight in water. The water soaked samples were wiped out and surfaces were dried. The samples were weighed with the help of a chemical balance before and after soaking. The moisture content on weight basis in the sample is defined as

Moisture content $=\frac{\text { Water soaked weight }- \text { Dry weight }}{\text { Dry weight }} \times 100 \%$

Thin mica sheets have been used to avoid electrochemical reactions (Tarkhov, 1947) at the electrode interfaces during measurement on moist sample to ensure better result.

Fig. 3 shows the variation of dielectric constant of different moist rock samples in the frequency range $10^{2}-10^{7} \mathrm{~Hz}$. Almost every sample shows a similar trend of variation as the trend shown by the dry rock samples. Due to moisture, dielectric constant shows a higher value as compared to presence of dry samples. In most of the samples an appreciable increase in the dielectric constant value has been observed in the lower frequency range as also reported by Howell and Licastro (1961).

Fig. 4 shows the variation of loss tangent of various moist samples in the frequency range $10^{2}-10^{7} \mathrm{~Hz}$. The variation of loss tangent shown in the figures shows a number of maxima and minima peaks in its cyclic variation and provides a negative and positive correlation as compared with the same sample shown at the room temperature.

In limestone, sandstone, quartzite, basalt and dolerite samples, the porosity of the storage pores is the major contributor to the total porosity. If the pores are fully saturated with water, the moisture content greatly affects the bulk dielectric constant since the dielectric constant of water is 80 (Katsube and Collett 


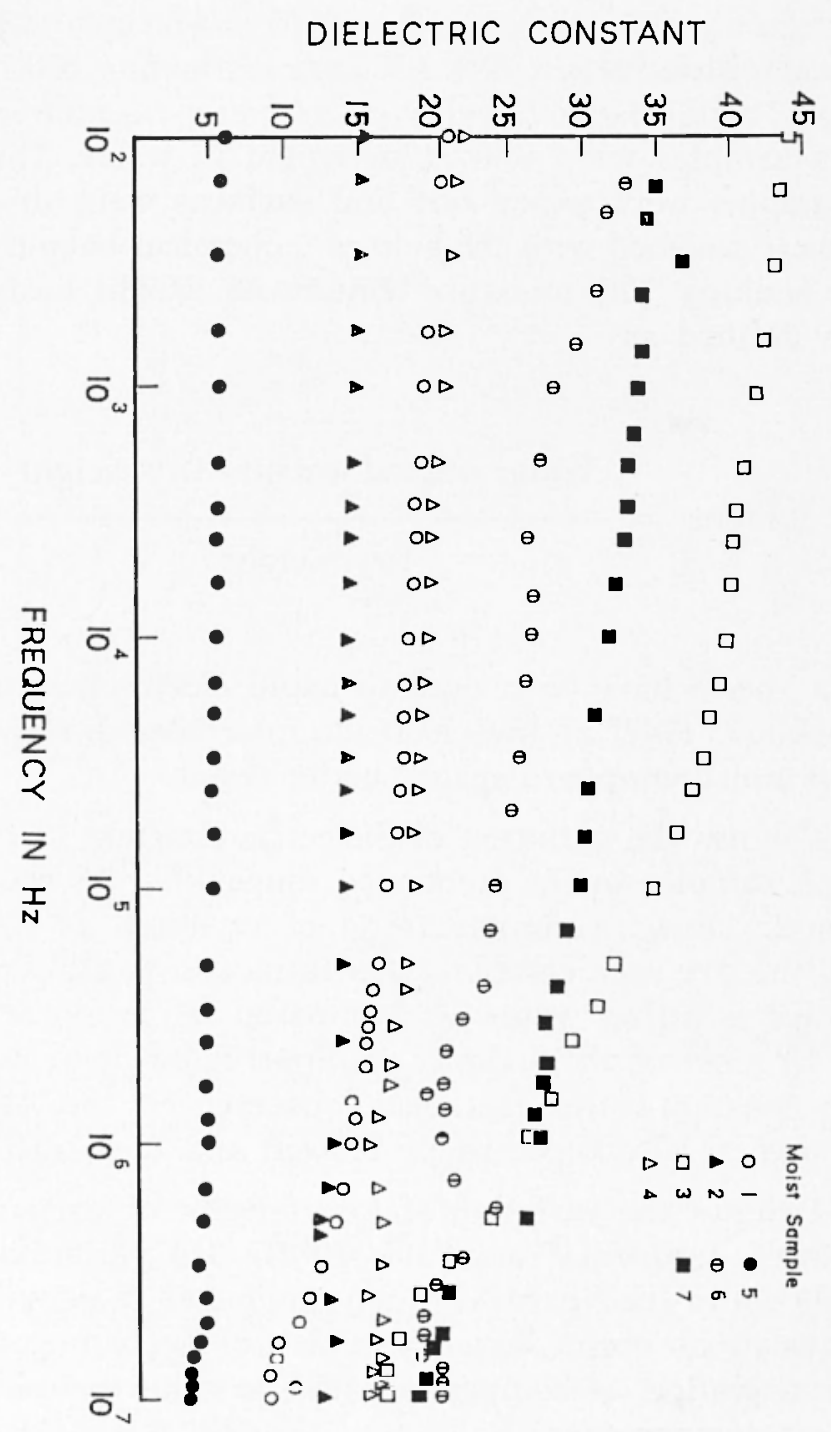

Fig. 3 - Variation of dielectric constant with frequency for moist samples (Sample 1 - Vindhyan sandstone, 2 - Vindhyan quartzite, 3 - Baraker sandstone, 4 - Marble, 5 - Limestone, 6 - Dolerite, 7 - Basalt). 
1976). Mineral composition plays a comparatively insignificant role on the dielectric constant of moist sample, the dominant

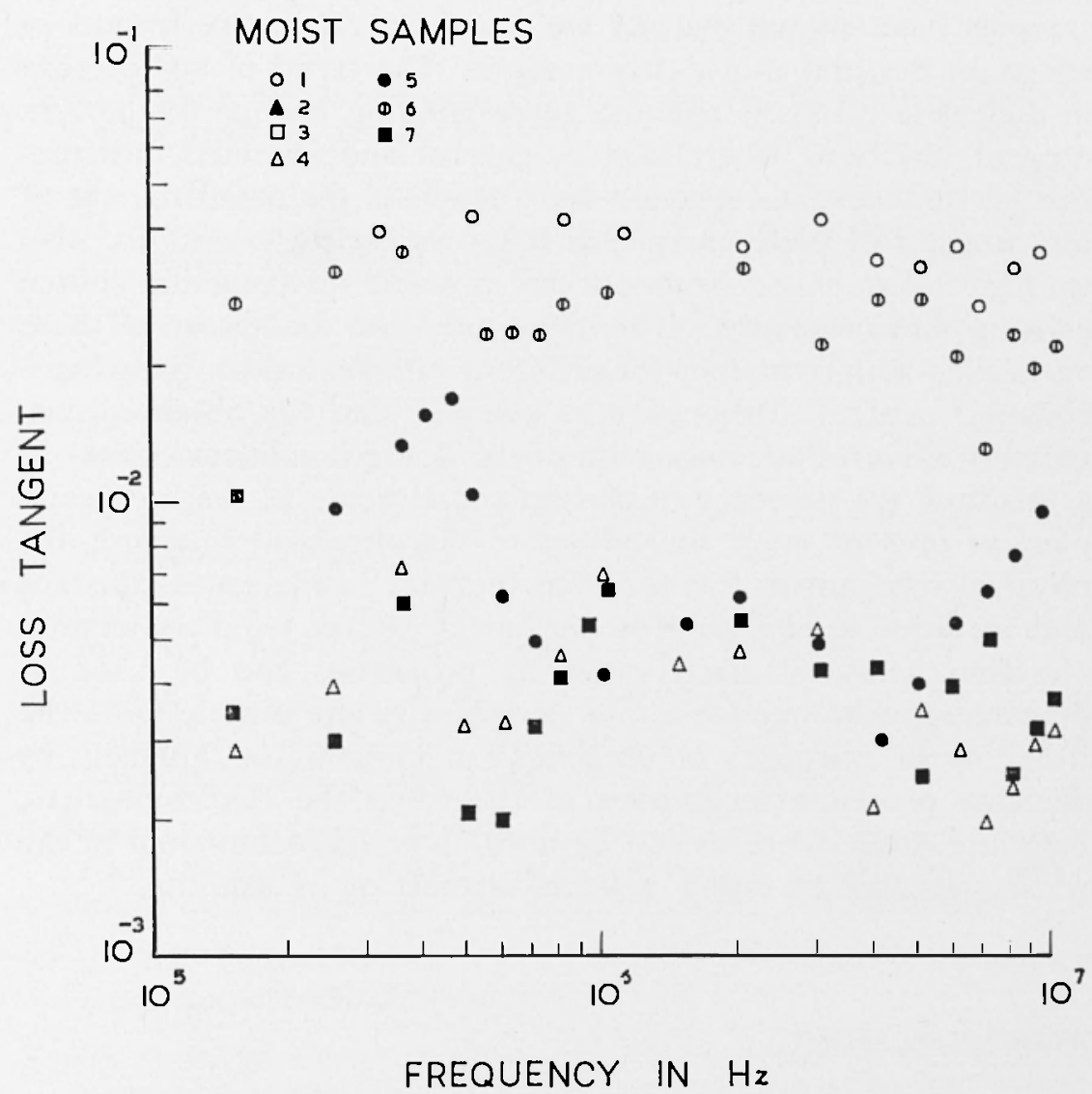

Fig. 4 - Variation of loss tangent with frequency for moist samples (Sample 1 - Vindhyan sandstone, 2 - Vindhyan quartzite, 3 - Baraker sandstone, 4 - Marble, 5 - Limestone, 6 - Dolerite, 7 - Basalt).

role is played by the existing pore spaces in the samples (Katsube) and Collet, 1971). In low porosity rocks, the dielectric constant of moist samples is mainly dependent upon the conductive minerals. 


\section{CONCluding Remarks}

The measured dielectric constant and loss tangent of various samples have shown distinct variations in the entire frequency range on dry and moist rock samples. The trend of an increase in dielectric constant and the corresponding change in the loss tangent has been ascertained by careful and repeated measurements. Due care has specially been taken in the measurement of loss tangent of these sample, as it shows typical variations. Also we have taken care to rule out any possible instrumental source causing these variations. The magnitude and the nature of these variations with frequency for different samples rule out any experimental artifact. Although it is believed that the observed characteristic variations may arise due to some non-linear effects as a result of the presence of certain constituents in the rock samples, at present stage any effort to visualise and interpret the physical mechanism for observed increase in dielectric constant and variation in loss tangent can hardly be free from conjecture.

The measured electromagnetic properties can be used as diagnostic technique for either deciphering one sample from the other or of purposes of classification of samples. Further, by devising precision techniques of recording the electromagnetic response, these features can be used as an important tool in the remote sensing by either balloon, aircraft or by satellite.

\section{ACKNOWLEDGEMENT}

One of us (RPS) is thankful to CSIR, New Delhi for financial support. We are grateful to Dr. Jagdeo Singh, Visiting Professor for his keen interest in this work. 


\section{REFERENCES}

BANKS, R. J., 1969 - Geomagnetic variations and the electrical conductivity of the upper mantle. "Geophysical J. R. Astr. Soc. ", 17, p. 457-487.

Brown, W. E., Jr., 1972 - Lunar subsurface exploration with coherent radar. In: "Lunar Geophysics ", Z. Kopal and D. W. Strangway eds., D. Reidel, Dordrecht-Holland, p. 243-257.

Dyal, P., Parkin, C. W., 1972 - Lunar properties transient and steady magnetic field measurements. "Moon », 4, p. 63-87.

FUlLeR, B. D., WARD, S. H., 1970 - Linear system description of electrical parameters of rocks. IEEE Trans. on Geoscience Elect., GE-8, p. 7-18.

HERMANCE, J. F., 1973 - An electrical model for the sub-icelandic crust. "Geophysics ", 38, p. 3-13.

Howell JR., B. F., LICASTRO, P. H., 1961 - Dielectric behaviour of rocks and minerals. "The american mineralogist", 46, p. 269-288.

Karsube, T. J., Collett, L. S., 1971 - Electrical properties of Apollo 11 and Apollo 12 Lunar samples. Proc. Second Lunar Sci. Conf. Geochim. Cosmochim. Acta, Suppl. 2, MIT Press, 3, p. 2367-2379.

Katsube, T. J., Collett, L. S., 1976 - Electromagnetic propagation characteristics of rocks. In "Physics and Chemistry of minerals and rocks", edited by R.G.K. Strens, John Wiley and Sons, U.K., p. 279-295.

Keller, G.V., Frischknecht, F. C., 1966 - Electrical methods in Geophysical prospecting. Pergamon Press, N.Y.

Keller, G. V., Licastro, P. H., 1959 - Dielectric constant and electrical resistivity of natural-state cores. Bull. USGC, 1052-H, p. 257-285.

LyTLE, R. J., 1974 - Measurement of earth medium electrical characteristics techniques, result and applications. IEEE Trans. Geoscience Elect., GE-12, p. 81-101.

Madden, T. R., Cantwell, T., 1967 - Induced polarization: a review. In: "Mining Geophysics », 2, SEG, Tulsa.

OlhoefT, G.R., 1976 - Electrical properties of rocks. In "Physics and Chemistry of minerals and rocks ", edited by R.G.J. Strens, John Wiley and Sons, U.K., p. 261-278. 
OlhoEFT, G. R., 1977 - Electrical properties of natural clay permafrost. Canadian J. of Earth Sciences, 14, p. 16-24.

Rossiter, J. B., La Torraca, G. A., Annan, A. P., Strangway, D. W., Simmons, G., 1973 - Radio interferometry depth sounding. Part II - experimental results. "Geophysics ", 38, p. 581-599.

Saint-Amant, M., Strangway, D. W., 1970 - Dielectric properties of dry Geologic materials. "Geophysics ", 35, p. 624-645.

TARKHOV, A. G., 1947 - Resistivity and dielectric constant of rocks in alternating current fields. "Materiali vsesuyz. nauchno-issl. geolog. instrument Geofizika », 12, p. 1-42.

Von VoOrhis, G. G., Nelson, P. H., Drake, T.L., 1973 - Complex resistivity spectra of porphyry copper mineralization. "Geophysics», 38, p. 49-60. 